\title{
Situation of the Health System in Honduras and the New Proposed Health Model
}

\author{
Lino Carmenate-Milián1, Alejandro Herrera-Ramos²*, Dany Ramos-Cáceres², Kathy Lagos- Ordoñez², \\ Tania Lagos- Ordoñez ${ }^{2}$ and Cesar Somoza-Valladares ${ }^{2}$
}

${ }^{1}$ Center for Research and Development in Health, Labor and Environment (CIDSTA) Coordinator, Department of Public Health, U.N.A.H, Honduras

${ }^{2}$ National Autonomous University of Honduras (UNAH), Honduras

${ }^{*}$ Corresponding author: Alejandro Herrera-Ramos, National Autonomous University of Honduras (UNAH), Honduras, Tel: +(504)32733646; E-mail: alejandroherreramd@outlook.com

Received date: June 27, 2017; Accepted date: July 06, 2017; Published date: July 10, 2017

Citation: Carmenate-Milián L, Herrera-Ramos A, Ramos-Cáceres D, Lagos- Ordoñez K, Lagos- Ordoñez T, et al. Situation of the Health System in Honduras and the New Proposed Health Model. Arch Med. 2017, 9:4

Copyright: (C) 2017 Carmenate-Milián L. This is an open-access article distributed under the terms of the Creative Commons Attribution License, which permits unrestricted use, distribution, and reproduction in any medium, provided the original author and source are credited.

\begin{abstract}
This article describes the current health system in Honduras including its composition, financing structure, coverage, employment and the impact of the health personnel migration. Likewise, a contrast is made with the profound reforms that are intended to be carried out in Honduras, which includes universal healthcare, increased coverage, and the inclusion of private providers in the new health model; it also involves the separation of roles between buyer and supplier. This last statement has generated controversy between sectors, members and professionals of the health services, which has associated it with the privatization of the health systems.
\end{abstract}

Keywords: Honduras; Health system; Reform; Social security

\section{Introduction}

The good functioning of health systems improves the health of the population, provide social protection, respond to the legitimate expectations of citizens, contribute to economic growth [1] and support universal coverage. The health system is currently experiencing difficulties because of its limited capacity to help reduce the gap in the unacceptable health exclusion situation. Weak governance, poor system management capacity, and rigid human resource administration make it difficult to streamline management to increase access to the general population to health services; all this summed up to the current crisis in the health sector [2]. The Honduran health system is characterized by fragmentation and problems of coordination and articulation between institutions and service units; this implies the duplication of activities, efforts and resources, among other aspects [3]. To situate the role of the state in the health system the constitution of the Republic in article 145 decrees that: "The right to health protection is recognized, the duty of all to participate in the promotion and preservation of personal and community health." The state will retain the appropriate environment to protect people's health ... and in Article 129 establishes the right to work stability [4]. According to the World Health Organization (WHO) on the performance of national health systems Honduras occupies position 131 of 191 countries [5]. The importance of contextualizing the role of the State in the health system is that only $2.9 \%$ of the population is covered by private insurance [6].

The Honduran health system in the two subsequent decades has had slight amendments, but they continue to use the same model of health and social protection for more than 50 years [7]. In recent years, health sector reform has been discussed in Honduras and because of health crises, a collapse of the care centers [2] and a severe financial crisis for cases of corruption [8], the process has accelerated. Despite being a very promising reform in many respects such as the extension of coverage, universalization and modernization of the health system; this has generated serious questioning in multiple sectors of Honduran society. Because the reform suggests autonomy in the management of private institutions health service providers are being the state and its institutions only governing bodies delegating their functions of financing, insurance and care to private providers [9]. The reform could have a negative impact on access to health services, the labour situation and the economy of the Honduran population. This is why a thorough review of the health system is being evaluated by evaluating its administration, financing, structure and human resources. Similarly, there is a contrast with the profound reforms that are intended to be made to the Honduran health system, its probable benefits and consequences based on the experience of reforms previously made in other countries of Latin America.

\section{Methodology}

A systematic review of documents of scientific societies, international body and governmental institutions, as well as of scientific articles and studies was carried out. Several documentary sources were used for the localization of bibliographic documents. Bibliographical search was carried out in PubMed, The Lancet, Scielo, official pages of foreign agencies \& governments and the State of Honduras. The search was 
limited to Spanish or English articles published between 2000 to 2016, 80\% published between 2012 to 2015 and being the only exception the Constitution of the Republic of Honduras published in 1982.

\section{Discussion}

\section{The Honduran health system}

The health sector consists of two subsectors. A public subsector composed by the Ministry of health (signal) corresponds to which the controller, guiding role and provision of health services to the entire Honduran population and the Honduran Institute of Social Security (IHSS) charge collect, manage fiscal resources and compulsory contributions from workers and employers. A private subsector made up of forprofit and non-profit institutions (Figure 1) [10]. HEALTH SECRETARY provides services to $60 \%$ of the population, IHSS secures $12 \%$ and private sector accounts for $10 \%$. In Honduras almost 9 out of 10 people are not covered by any kind of health insurance and it is estimated that $18 \%$ of the population (more than 1.5 million Hondurans) do not have access to health services (Figure1) [11].

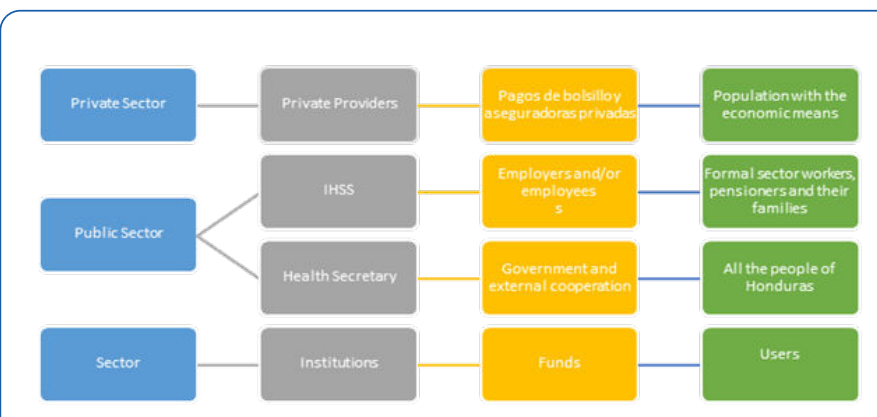

Figure 1: Current health system in Honduras.

\section{Organization, infrastructure and technologies}

The hospital infrastructure and health centers are deficient; the services are not of the required quality and coverage. Some public centers date from the beginning of the last century and require heavy investments in infrastructure and equipment to provide the services in optimal conditions and free of risk. Maintenance has been scarce and has led to the constant deterioration of both infrastructure and equipment [9].

The network of services of the Secretary of Health is divided into two levels. The second level has 29 units (hospitals) and units are classified into three groups: national hospitals, regional hospitals and area hospitals [11]. Most of the hospitals date back to 1980, the only ones with new facilities being the hospitals in the cities of Tela, Danlí [9] and more recently the Maria Hospital for Paediatric Specialties (HMEP) in Tegucigalpa. The HMEP, which despite its construction in 2004 did not enter into service until 2014 [12] and did not expand budget for it, simply transferred budget, rooms and health personnel that belonged to the Hospital for Maternal and Child Care (HMI) towards the HMEP weakening other institutions and not extending coverage [13]. With regard to the primary care network, it is provided in its first level mainly in the Rural Health Centers (CESAR) and in the Health Centers with Physician and Dentistry (CESAMO). The HEALTH SECRETARY services network has 1,635 establishments: 7 national hospitals (located in Tegucigalpa and San Pedro Sula), 6 regional hospitals, 16 area hospitals, 436 CESAMO, 1,078 CESAR, 74 maternal and child clinics, 3 peripheral emergency clinics (CLIPER) and 15 dental school centers (CEO) [14]. The IHSS only has 2 hospitals located in San Pedro Sula and Tegucigalpa, 7 peripheral clinics, 1 dentistry center, 2 physical medicine and rehabilitation centers and 1 center for elderly care [7]. The private sector has 1,131 establishments, which include medical centers, clinics, laboratories, pharmacies and medical offices.

The national total of beds available are 6,590. Out of that 5,059 beds are of the Health Secretary (public sector), 916 of IHSS, 40 of the military hospital and 575 beds in the private sector [7]. This data represents a number of 9.5 hospital beds per 10.000 inhabitants [15], a coverage of 0.4 hospitals per 100 000 inhabitants (penultimate place in Central America [CA] only surpassed by Guatemala), 2.1 computed tomography units per million inhabitants, 0.7 radiotherapy units per million inhabitants (fifth place in CA surpassing only Belize and Nicaragua), 31.6 mammography units per million women of 50-69 years (in the penultimate place only surpassing $\mathrm{El}$ Salvador) [16].

\section{Financing and budget}

In Honduras, total health expenditure as \% of GDP is $8.5 \%$, being lower than the average for the Americas (14.1\%) [16]. According to the Economic Commission for Latin America and the Caribbean (ECLAC), Honduras ranks second at the CA level and fourth in Latin America. According to public health expenditure as a percentage of GDP [17]. As a region Central America (CA) it increased by little more than 1.5 times the public investment in health per capita [18]. However, one of the lowest levels of investment corresponds to Honduras at $\$ 101$ per person. This is still very low in the context, with only a quarter of the average in Latin America and the Caribbean (\$392 per person), about one-seventh of the average ( $\$ 628$ per person) and well below the investment of the Organization for Economic Cooperation and Development (OECD) nations (\$2,880 per person) (Figure 2) [18].

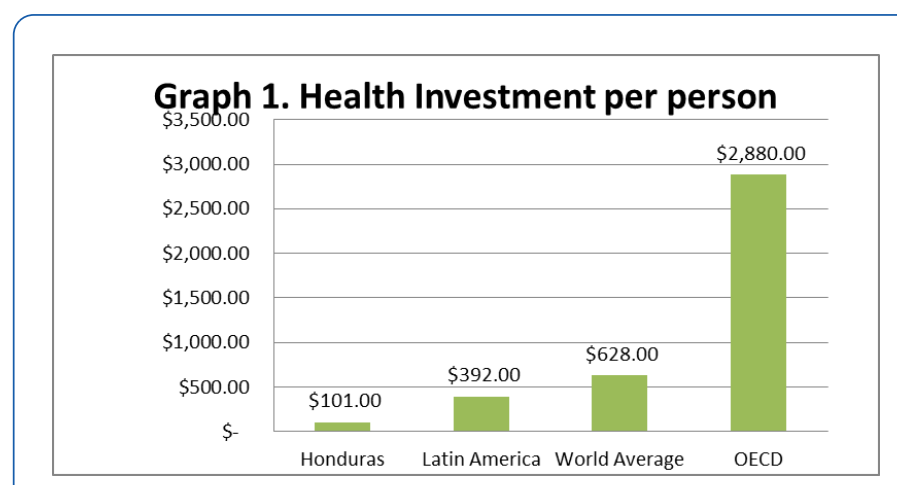

Figure 2: Health investment per person. 
The Health sector accounts for $11.5 \%$ of total expenditures of the national budget. This has declined by $3.7 \%$ in the last 5 years [19] and for the 2017 budget a decrease of $4.51 \%$, or more than 6.5 million lempiras, is expected [20]. The decrease in the health sector was due in part to the transfer of budget to other institutions that required budgetary space, as well as to the budget freeze due to cost containment [21]. At present, the main sources of health financing in Honduras are $54.7 \%$ government, $34.4 \%$ of households as out of pocket expenses and $8.2 \%$ of external cooperation [22]. According to the annual budget of the Secretary of Health $76 \%$ of funds invested in health comes from the National Treasury, 11\% from external loans, $9 \%$ from donations and, recently, $4 \%$ from national debt relief. $57 \%$ of the budget of the Ministry of Health is earmarked for wages, $6 \%$ for service contracts, $21 \%$ for materials and supplies, $5 \%$ for capital goods and $11 \%$ for transfers and subsidies.

\section{Coverage}

The medical staff has 8 hours a day in which they must attend a maximum of 36 patients and the vast majority of these staffs attend patients in the hours of 07:00 a.m. At 1:00 p.m. In such a way that the health centers are practically without medical attention in the afternoon and weekends, when only emergency is attended [9]. In 2015, there were 10,995 registered doctors [23]. In terms of health personnel, it is estimated that there are 10.1 doctors per 10,000 [10]. Data by departments showed differences: Francisco Morazán had 23.8 doctors per 10,000 inhabitants while Lempira and Santa Barbara each had 2 doctors per 10,000 inhabitants. None of the 18 departments meet the minimum indicator of 25 physicians per 10,000 inhabitants as indicated by the regional human resources target (Figure 3 ) and in contracting with the average of the region of the Americas there is an unequal gap (20.8 physicians Per 10,000) [24].

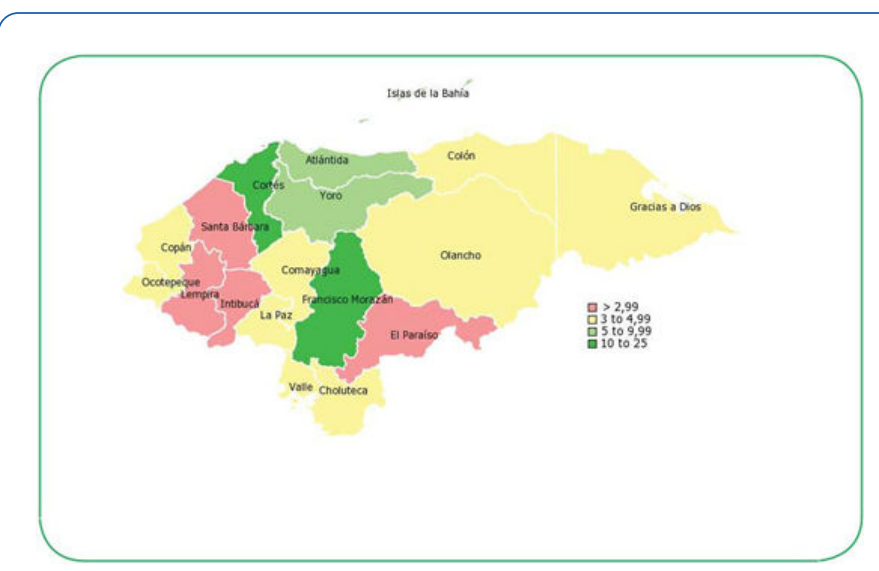

Figure 3: Density of doctors per 10,000 in Honduras.

In 2010, the number of collegiate dentists was 2,522, of which 190 (7.5\%) worked for the Secretary of Health. Dentists have a rate of 0.2 per 10,000 inhabitants [3]. The WHO does not mention a standard of dentists [25], but the difference is exorbitant with respect to the region of the Americas (6.9 dentists per 10,000 inhabitants) [16]. With regard to professional nurses is 2 nurses per 10,000 inhabitants, and 8 auxiliary nurses per 10,000 inhabitants [24] being low compared to the WHO recommendation of 50 nurses per 10,000 [26]. In fact, in the health system there is a critical lack of technical personnel, specifically in the areas of X-rays, anesthesiology and laboratory, lacking adequate planning and without the sufficient national capacity to train human resources in these areas [9].

\section{Medical employment situation}

In Honduras there is a very outdated human resources policy and there is no planning in the field or coordination between the different instances involved [2]. In 2015, the Health Secretary had 2,546 permanent physicians (63.2\%) [11], private sector with 880 physicians $(23.9 \%)$ and IHSS with 474 physicians (12.9\%) [3]. Speaking only in the context of Health Secretary which is the largest employer in 2015 had 23,954 employees of which only $13 \%$ medical professionals [11], this has been gradually reduced since 2008 which medical professionals represented $22.9 \%$ of the staff [3]. The $68.34 \%$ are women and the rest $31.66 \%$ are men, which confirms the trend towards the feminization of health workers. This represents an unemployment rate of $46 \%$ of the 10,995 registered doctors [24]. In 2014, there was a significant adjustment and wage control due to the agreements signed with the International Monetary Fund (IMF) and the World Bank (WB) to reduce the wage bill. In the last 15 years the salaries paid by the Central Administration have decreased by $6 \%$ only in the period of 2013 and 2014 was reduced by $2.3 \%$, this is due to the transfer of the payroll from the University School Hospital to the National Autonomous University Of Honduras (UNAH) who is currently administering it. The decrease in the payment of salaries in the health sector is the result of the beginning of the process of revision and purification of the payrolls [21]

\section{IHSS crisis}

The current situation of calamity that has been provoked by the inefficient historical administrations of IHSS is evident. The related facts have provoked a crisis in IHSS that have affected the human right to social security of the Honduran population. The budgeted income for the year 2014 was not reasonable because of the accounting deficiencies, since values are being recorded in concept of quotation of non-existent companies, fact that is currently under investigation [8]. In order to strengthen the financial position of IHSS from October 2011, it was authorized that the wage base of contribution will pass from $L 4,800.00$ to $L 7,000.00$, this allowed an increase in the surplus of $97 \%$ for the year 2012 and $86 \%$ for 2013; However, these figures concealed the reality of the institution that accumulated significant amounts of debt to suppliers and was the subject of a series of irregular operations [21] of a total of $L$ $290,907,683.98$ [27], which imposed serious limitations for its operation. In 2014, there was a 5.5\% reduction in income from IHSS contributions. This has its origin in the fall of the contributions of the public sector by the restructuring that the state institutions have made (mergers, closing of entities, cutback of personnel). On January 15, 2014 the IHSS intervention began (Executive decree PCM-No. 011-2014) with the purpose of identifying with precision the problematic of the 
institution, as well as proposing and implementing the appropriate course of action for its financial rescue and administrative improvement [21]. The Social Security Administration period 2010-2014 has incurred in civil, criminal and administrative responsibilities in making commitments and making payments outside budget allocations [8].

\section{Migration}

The migration of professionals to more developed countries is a problem in most countries [28] and Honduras is a country highly exposed to migratory processes. In 2012 Honduras represented $11 \%$ of the applicants to the Spanish program of resident internal medical training (MIR) of the $C A$ region and Dominican Republic and is in position 12 according to the total number of foreign applicants to the MIR [29]. The percentage of physicians, surgeons and dentists born in Central America employed in U.S. Civil Labor represent $10 \%$ of the female foreign workforce and $16 \%$ of the male foreign workforce [30]. It has been estimated that between 1996 and 2010, 5.017 health professionals from Honduras would have emigrated. The costs of training per pupil of a health professional in Honduras are: Doctors in public university $\$ 99,936$, doctor in private university $\$ 116,578$, nurse in public university $\$ 78,579$ and nurse in private university $\$ 89,962$. The annual cost of emigration of health professionals in Honduras would range between \$4,089 and $\$ 3,592$ million dollars [29]. There are studies regarding the intention of medical students to migrate which stated that students whose parents had higher levels of education had more pretensions to work abroad and had less intention to work in a rural area [31]. In a situation of this nature, which is the one faced by several of the nations of the region, any government would be in full right to promote the retention and return of its qualified personnel [32].

\section{The New Health Model}

Health model reforms in Latin America are not something new. Since the 1990s, reforms have been observed in Latin America in four major areas of change: the reorganization of structural fragmentation systems, decentralization, optimization of regulatory functions and separation of financing (i.e. buyer) and provider functions to improve the efficiency of the health system. 1 The proposed new model in Honduras contains reforms in the four areas, mainly in the area of separation of financing.

The health sector reform postulates the strengthening of the guiding role of the Ministry of Health and the separation of the essential functions of financing, securing and provision of services. It also includes the development of relevant actions so that, in the long term, these functions are awarded to other institutions [3]. Another initiative, framed in the reform process, has been the provision of autonomy in management, articulated through agreements or management contracts with the private sector. For this purpose, production parameters, quality criteria, incentives are set and the financing is adjusted according to the actual cost of the service produced. Consequently, financial information systems, costs and healthcare production have been developed. Services will be provided through third-party providers and the State shall ensure payment. In order to separate the funding, securing and allocating resources to the service delivery function will result in a transfer of risk to local managers administering the provision, through a system of incentives or rewards to good management, or with penalties for non-compliance with objectives and goals [9]. The providers of health services of the country are organized in a national network of Integral Health care consisting of municipal or inter municipal networks, which in turn are organized in micro-nets of the first level of attention and second level of attention (hospital) thus replacing the current model (Figure 4). It will be compulsory for the health care units to join a network [33] although so far it has not been cleared up if such affiliation will cost. According to the position of the Honduran Medical College (CMH) the proposal for this reform disappears public health in Honduras [34] and the privatization of health systems makes the right to health a privilege supervised under the lines of banking and privatization systems [35].

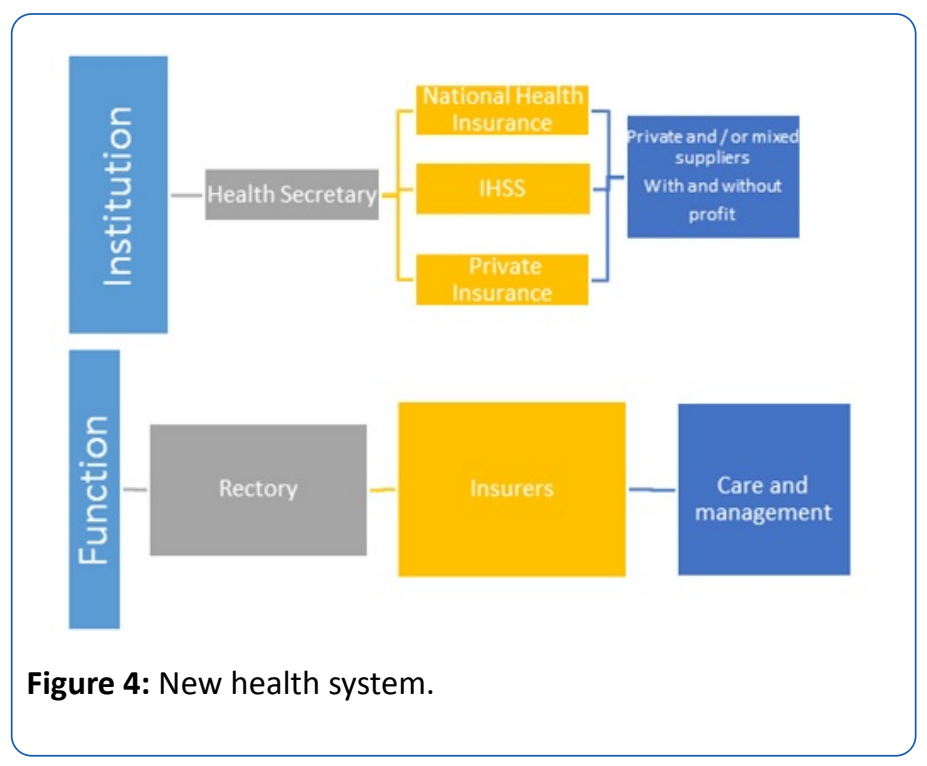

\section{Levels of care and organization}

It will be formed in two levels of attention: first and second level. The first level of care will be the first door to the health system, provide ambulatory care and have the highest demand for attention. This is divided into 3 levels of complexity according to its staff and equipment. This level basically comes to replace the terms Cesar, CESAMO, Clipper and CEO of the current model. The second level should ensure the continuity of the process of attention to health problems, which by their level of complexity are referred from the first level. They will offer emergency services, hospitalization and surgical care. This in turn is divided into 4 levels of complexity and comes to replace the terms of Area hospital, Regional Hospital and National Hospital of the current model. Attention levels and reference details are set out in Table 1. Without an investment in infrastructure the risk of a system collapse will continue because the country has only two hospitals of complexity hospitals level 6, three complexity hospitals level 7 that are all located in two cities (San Pedro Sula and Tegucigalpa), limiting thus its coverage capacity. The country has only three highly specialized hospitals: a psychiatric care 
hospital, a pediatric specialty hospital and a cardiopulmonary institute [22].

Table 1: Categorization and classification of health establishments in new health model.

\begin{tabular}{|c|c|c|c|}
\hline Attention Level & Levels of Growing Complexity & $\begin{array}{l}\text { Category and type of } \\
\text { establishment }\end{array}$ & Distinctive characteristics of health establishments \\
\hline \multirow[b]{3}{*}{ First Level } & Level of complexity 1 & Health Center Type 1(HC Type 1) & Rural outpatient clinic with general practitioner \\
\hline & Level of complexity 2 & Health Center Type 2(HC Type 2) & $\begin{array}{l}\text { Urban outpatient with general practitioner, addresses } \mathrm{HC} \\
\text { Type } 1 \text { reference }\end{array}$ \\
\hline & Level of complexity 3 & Health Center Type 3(HC Type 3) & $\begin{array}{l}\text { Urban ambulatory with basic medical specialties, without } \\
\text { Internment, may have short-stay beds ( } 12 \text { hours }) \text { and } \\
\text { Addresses HC Type } 2 \text { reference }\end{array}$ \\
\hline \multirow[b]{4}{*}{ Second level } & Level of complexity 4 & Hospital Type 1 & $\begin{array}{l}\text { General Hospital with basic specialties. Addresses } \\
\text { references to the First level }\end{array}$ \\
\hline & Level of complexity 5 & Hospital Type 2 & $\begin{array}{l}\text { Specialty Hospital and Sub specialties, attends patients } \\
\text { Referrals from Type } 1 \text { hospitals }\end{array}$ \\
\hline & Level of complexity 6 & Hospital Type 3 & $\begin{array}{l}\text { Specialty Teaching Hospital. Attends referred patients of the } \\
\text { Type } 1 \text { and } 2 \text { hospitals }\end{array}$ \\
\hline & Level of complexity 7 & Hospital Type 4 & $\begin{array}{l}\text { University Hospital and highly specialized Institute of national } \\
\text { reference }\end{array}$ \\
\hline
\end{tabular}

\section{Universalization}

Universal health coverage is an important way of expanding access to effective health care services, reduce financial difficulties during illness and improve health outcomes [36]. Currently there are two different conceptions about what to understand by universal right to health. There is, on the one hand, the concept of Universal Health Coverage (UHC) based on the assurance that covers a restricted package of services. On the other hand, there is the conception of achieving it through a unique, public and free health system to guarantee equal access to all before the same need known as the Unified Health System (UHS) [37]. In Honduras it is proposed the universalization of insurance with a UHC approach through an integrated and plural health system, in which the Health Secretary apart from its governing function would have a national public health insurance for the poor and an IHSS that would function exclusively as an insurer when contracting services for its affiliates with public and private providers that would operate under a model of family and community health [7].

\section{Coverage and care}

The reform aims to achieve 95\% health coverage at all levels of the system. Defining the horizon for the health sector [2]. The coverage in care will not be total (all diseases), but the reform contemplates specific complementary packages whose access will be guaranteed to special segments of the population (selective coverage), for particular reasons. This same model defines specific packages as "a limited set of interdependent health services and services that are thought to be provided to certain special groups ..." [22]. The reform does not refer to the investment of the state or financial institutions in new infrastructure in geographic areas where there is no coverage, but rather establishes the delegations of state institutions previously operated in the country to private institutions.

\section{Financing}

The financial sustainability of the health system will be made through the combination of direct, indirect and contributory contributions [9]. The financing will be based on the tendency to progressivity, which is defined as "an equitable tax, a taxpayer with higher income must pay more ..." being the payment proportional to their income. A health social protection system will be developed with a subsystem of public health insurance that will be financed by a single national health fund [22] (PROSOLIDAR PLAN) [33], the IHSS whose income will come from direct taxes and Mandatory contributory contributions from the IHSS and a private contribution that will imply the definition of a mandatory health plan.

Social protection encompasses two basic subsystems: the private health insurance subsystem (private SAS) and the public assurance subsystem (public SAS). The private SAS is constituted by the insurance companies that operate in the country under the guidance of the banking and insurance commission, more specifically the superintendence of insurance and pensions, which offers health insurance, accidents and life damages [22].

The public SAS, according to the current legal framework, would be developed within social security and under the protection of the IHSS. Within the public SAS there will be two contributory components that include the mandatory and special regimes contemplated in the law of social insurance and the non-contributory; And this in turn is divided into two regimes: the subsidized regime that will include health insurance actions financed totally or partially with funds from the treasury and the system of casualty coverage that includes high-risk social events and that by nature should be financed through fees and charges that the Finance Secretary must propose [22].

There is a latent fear among different sectors of the country in the participation of for-profit entities within the reform of the Honduran health system because private entities were related to 
the crisis of the IHSS and could produce a new crisis of the entire health system Honduran more acute than the present one. Another major challenge to the integration of private providers is the price increase in health services because they are forprofit organizations, in a country with an estimated per capita national income (GNI) of $\$ 1,880$, where $64.5 \%$ of the population lives below the poverty line [38]. 39.7\% live in extreme poverty [39]. In new model of health, the state states that, its resources will not be "ever enough", thus delegating its functions to individuals, family communities, local government, managers, suppliers and other agencies.

\section{Payment mechanisms to suppliers}

The payment mechanism is defined as the different types or forms of financial remuneration to health service providers by the insurance or financing institutions. The state conditions the supply, demand and management of the services [22]. Contradicting the law of supply and demand, it is injuring the free market [40].

\section{Human resources and research}

Investment in the scientific and technological area in Honduras is $0.04 \%$ in relation to GDP, below the regional level of Latin America (0.69\%) [41]. The reform only makes reference to old teaching agreements [22]. It does not plan any new investment in research and training of human resources. Honduras lacks multiple specialized training programs and most hospitals do not offer a field to trained specialists [10]. This could be another point in which the decentralized entities should offer scholarships or subsidies in the formation of their personnel and thus be able to offer an attention of optimum quality with competitive personnel at a global level.

\section{What were the impacts of similar reforms in Latin America?}

Beginning in the late 1980s, many countries in Latin America initiated social sector reforms to alleviate poverty and reduce socio-economic inequalities, including reforms in the 1990s to strengthen health systems and introduce universal health coverage [42]. Health reforms in Latin America are taking place in two opposing ways: the Universal Health Coverage (UHC) and the Unified Health System (UHS) [37].

The most known cases of UHC in Latin America are Chile, Colombia and Mexico [37]. Chile with compulsory insurance, parallel public and private systems; Colombia, with compulsory insurance and competition between various fund managers and providers; And Mexico, with a mixed system of compulsory and voluntary insurance. The three systems have different health insurance plans, depending on the amount of the premium, public subsidies and transaction costs [40].

In Chile the reform gave rise to two parallel systems: the Private Health Institutions (ISAPRE) with private providers and the public of the National Health Fund (FONASA) with public providers [43]. The segmentation of the health system was thus maintained and the fragmentation of its private component increased. Health packages in the private sector depend on the quoted amount and there is exclusion of high risk persons (old or sick); Problems that have been later narrowed with the establishment of explicit health guarantees [37].

The Mexican reform gives rise to three forms of insurance: social insurance for formal workers, Seguro Popular (SP) for the uninsured and the private. The financing is tripartite with an important fiscal subsidy for the first and mainly fiscal for the SP, with the payment of a premium by the insured. The service packages are different and the SP does not cover more than $20 \%$ of social insurance services and excludes most of the high-cost illnesses that are treated by the patient. Both subsystems have their public providers with their own infrastructure and salaried personnel but can contract with the private sector [44]. The reform process has weakened social insurance, the most solid part of the public health system, and has not achieved universal insurance coverage; With $25 \%$ of the population without insurance [37]. Legally there is a separation of functions between administration of funds/purchase of services and provision of services but there are no private administrators despite attempts to promote them since 1995 [45]. Currently a new reform aims at the portability of insurance between public and private institutions with a unique package of services, unique treatment protocols, cost-effective services and health market development through the creation of a "Universal National Health System" (SNSU) [46].

On the other hand there are countries that followed a SUS model. In Brazil the coverage went from 30 to 190 million people with the Brazilian SUS and $98 \%$ of the population was able to access the services in search of them [43]; In Venezuela the Barrio Adentro program expanded access to 17 million people (57\% of the population) who lacked it [37]; In Ecuador, access increased substantially with free services and medicines [47], and in Uruguay, the new policy has favored the previously underserved rural population [48]. Although it has also been a feature of the health policy based on the UHC, governments with policies of a SUS have also increased the health budget [49]. The difference between the two is that governments with SUS model have strengthened the budget of the public sector whereas in the government with the UHC model their increase in budget has been used by the private sector [37].

Reform models such as the one proposed in Honduras, according to the Latin American and Caribbean Medical Confederation (CONFEMEL); represent "the advance of the privatizing trend to the detriment of State participation" [50]. There is a definite need for a rescue of the Honduran health system, but it seems that reforms will be implemented without consulting with all the sectors that will be affected and / or benefited (employees, users, subsidized, private companies, and the medical guild). Many sectors fear that just like in Colombia where a significant increase in coverage occurred, reaching levels above $90 \%$ today [51]. Simultaneously it resulted in a nondefined public health policy, epidemiological surveillance systems are almost non-existent, State payments to decentralized entities are not agile, there are delays of up to one or two years, medical fees have been frozen for more than Ten years, corruption by government and private managers [52]; And the economic deficit of the public network of Hospitals 
exceeded 600 million Euros, reason why the approximately 33,000 medical centers, laboratories and hospitals run the risk of disappearing.

\section{Results and Conclusion}

It will not be possible to achieve universal coverage without a strong investment in modernization of infrastructure, human resources and budget increase, which will need to be supply by the private and/or public sector not taking over the management of former hospitals but generating new investments in regions where there is no Adequate coverage.

The UHC models challenge the idea of the right to health as a social and human right and set out on the road to commodification. This policy premise that the market is the best distributor of resources and that competition improves quality and cuts costs.

The new division of responsibilities places private providers, for-profit companies or the family/individual at the center, while the role of the state is subsidiary and only serves the most vulnerable sectors.

Honduras lacks data and updated research so it is necessary to include research and data collection within reform policies regardless of the health model to follow. This article describes an overview of the health system and its reforms but it is necessary in future reviews and investigations to deepen in subjects such as the migration, the unemployment and the development of human resources in health professionals; Likewise when it comes into force to register and publish the achievements and deficiencies of the reforms or health model that is implemented in Honduras.

The country has a high deficit of coverage of professional physicians, however $46 \%$ of physicians are unemployed and this workforce can reduce the deficit in coverage. Otherwise, the brain drain will continue to grow in the health sector, especially among professional doctors and nurses. This would represent an annual loss to the country of $\$ 4$ billion Dollars and therefore it is essential to carry out strategies for the return of human resources, especially those with specialized knowledge.

A reform of the Honduran health system is necessary, but it must ensure universal, equitable, fair and not only guarantee coverage but access to the entire population, respecting its constitutional right to health and human rights.

\section{Conflict of Interest}

The authors declare no conflicts of interest.

\section{Disclaimer}

This article is already published in the Spanish Journal Archivos de Medicina. This is the English version of the article. The consent has been obtained from the authors.

\section{References}

1. Tuna R, de Andrade Lo, Almeida G, Cotlear D, Dmytraczenko T, et al. (2015) Health-system reform and universal health coverage in Latin America. Lancet 385: 1230-1247.

2. Government of the Republic of Honduras Signal (2014) National Health Plan 2014-2018. Tegucigalpa, Honduras.

3. Pan American Health Organization (PAHO) (2012) Health in the Americas.

4. Political Constitution of 1982 (1982) National Constituent Assembly. Decree No. 131. The Gazette No. 23612.

5. World Health Organization (WHO) (2000) World Health Report 2000. Improve the performance of health systems. Geneva, Switzerland.

6. Maceira D (2014) Quadrants of analysis in the health systems of Latin America. Unicef. Working documents cedes 122/2014. Buenos Aires, Argentina.

7. Bermúdez-Madriz JL, Sáenz Mr, Muiser J, Acosta M (2011) Honduras Health System. Public Health Mex 53: s209-s219.

8. Morales V, Leitzelar G, Salinas R (2014) First report of the auditing Committee of the Honduran Social Security Institute (IHSS).

9. Secretary of Health (Signal) (2005) National Health Plan 2021 Tegucigalpa, Honduras.

10. Pan American Health Organization/World Health Organization (PAHO/WHO) (2009) Profile of health systems Honduras. Monitoring and analysis of the processes of change and reform. Washington, DC

11. Institute of Access to Public Information (2015) Single portal of transparency. Secretary of Health.

12. Secretary of Health (Signal) (2014) Salud Inaugurates Maria Hospital. Rev Saludhn 14: 10-11.

13. Alvarenga C (2014) Transfer of 30 Physicians from School hospital to María hospital. Pres Univ.

14. National Human Rights Commissioner (Conadeh) (2014) First special report on aspects of the Public health service in Honduras. (The human right to health and the Public Health service). Tegucigalpa, Honduras.

15. World Health Organization (WHO) (2012) World Health Statistics 2012. Geneva, Switzerland.

16. World Health Organization (WHO) (2014) World Health Statistics 2014. Geneva, Switzerland.

17. United Nations Organization (UN) (2015) Economic Commission for Latin America and the Caribbean (ECLAC). Statistical Yearbook of Latin America and the Caribbean, 2015 (LC/G .2656-P). SANTIAGO, Chile.

18. Fifth state report of the region in sustainable human development 2016. A report from Central America and Central America. State of the Nation-region program. Guans-Costa Rica.

19. Secretary of Finance (Sefin) (2011) Memory 2010. Presented to the Sovereign National Congress. Tegucigalpa, M.D.C., Honduras.

20. Secretary of Finance (Sefin) (2016) general provisions of the general budget of income and expenses of the Republic 2017. Tegucigalpa, Honduras.

21. Secretary of Finance (Sefin) (2015) Memory 2014. Presented to the Sovereign National Congress. Tegucigalpa, M.D.C., Honduras. 
22. Secretary of Health (Signal) (2013) National Health model for a healthy Honduras. 2013 Tegucigalpa, Honduras.

23. Central Bank of Honduras $(\mathrm{BCH})$ (2015) Honduras in figures 2013-2015.

24. National Autonomous University of Honduras (Unah) (2009) Faculty of Medical Sciences. Postgraduate in public health. Pan American Health Organization. Analysis of human resources situation in health of Honduras 2009.

25. Soledad KS (2014) Dentists of the public network: Coverage v/s number of professionals. J Oral Res pp. 137-138.

26. International Council of Nurses (2015) Nurses, a force for change: Effective in care, cost-efficient. 2015 by ICN-International Council of Nurses. Geneva, Switzerland.

27. National Congress of Honduras (2015) Multi-party Commission appointed by the President of the National Congress for: To investigate developments related to the case of corruption of the Honduran Institute of Social Security IHSS and other cases in which the citizens have a special interest in their high social impact, having to give, within the legal term of twenty days, the corresponding report. Tegucigalpa MDC, Honduras.

28. Health agenda of Central America and Dominican Republic 2009-2018 (2009) United for the health of our peoples. Adopted at the XXIX regular meeting of the Council of Ministers of Health of the Central American Integration System Tegucigalpa.

29. Pan American Health Organization (PAHO) (2016) panorama of the migration of physicians and nurses in the region of Central America and the Dominican Republic.

30. Stoney S, Batalova J (2013) Central American immigrants in the United States. Migration Policy Institute. Washington DC.

31. Zambrano Li, Pereyra er, Reyes Sz, Fuentes I, Mayta P (2015) Influence of parental education on Honduran medical students Labour perspectives: rural work and emigration. Can J Rural Med 20: $121-128$

32. International Organization for Migration (2009) The emigration of qualified human resources from Latin American and Caribbean countries. Contemporary trends and perspectives. CARACAS, Venezuela.

33. Legislative power. Decree No. 56-2015. Framework law of the social protection system. The Gazette. Section to agreements and Laws No. 33.771. Tegucigalpa, M.D.C., Honduras.

34. Honduran Medical College (CMH) (2015) Statement: Position of the Medical College of Honduras in the proposal for a draft framework law of the social protection system. Tegucigalpa.

35. Medical College of Honduras (CMH) (2016) Extraordinary Assembly report 3 December 2016.

36. Tuna R, Aydin S, Chakraborty S, Sumer S, Aran M, et al. (2013) Universal health coverage in Turkey: Enhancement of equity. Rev The LAN Jour 382: 65-99.

37. ASA Ebba CL (2016) Competing health policies: Insurance against universal public systems. Rev Lat-Am Enfermagem 24: e2668.
38. Social Fund of external debt and Development of Honduras (Fosdeh) (2014) Analysis of poverty in Honduras. Characterization and analysis of determinants, 2013-2014. Tegucigalpa, Honduras.

39. United Nations Organization (UN) (2016) Executive Board of the United Nations Development Programme, The United Nations Population Fund and the United Nations Office for Project Services. DP/DCP/HND/3. Program document for Honduras (2017-2021). Second regular session of 2016. New York.

40. Mankiw NG (2012) Economics principles. (6th edn), printed in Mexico, Mexico, D.F.

41. National Autonomous University of Honduras (Unah) (2014) Advances in scientific research in Honduras. Rev Inv and Cienc 4: 3-4.

42. Tuna $R$ (2012) health systems, systems thinking and innovation Rev Oxf Jour 27: 4-8.

43. Heredia N, Laurell AC, Feo O, Noronha J, Gonzáles-Guzman R, et al. (2015) The Right to health: What model for Latin America? Rev The Lanc Jour 385: 34-37.

44. Bitran R (2013) Unico Studies Series No 21. Explicit health guarantees for Chileans: The auge benefits package. The World Bank's Universal health Coverage Studies Series (Unico.) Human Development Network. Washington DC.

45. Laurell AC (2013) Impact of the popular insurance in the Mexican health system. (1a edn.), Autonomous City of Buenos Aires.

46. John M (2014) towards a national universal health system. Ministry of Health 82: 98-108.

47. South American Institute of Government in Health (isags), Unasur (2012) Health Systems in Southamerica: Challenges for universality, integrality and equity.

48. Borgia F, Gluttony A, Gabrielzyk I, Azambuja M, Soto J, et al. (2012) The invisibility of the situation of the community-rural polyclinics in Uruguay to the prioritization of rural health as a public policy. Saúde debate 36: 421-435.

49. Laurell AC (2014) Health contradictions: On accumulation and legitimacy in the neoliberal and social governments of law in Latin America. Saúde debate 38: 853-871.

50. Latin American and Caribbean Medical Confederation (CONFEMEL) (2016) Brasilia declaration. Ordinary General Assembly, Brasilia DF, Brazil.

51. Bernal O, Gutiérrez C (2012) Health in Colombia achievements, challenges and recommendations. Bogotá: Universidad de los Andes, School of Government, Uniandes Editions, 2012.

52. Borrego Salazar Ja, Gómez Rojas La (2013) Case Study: "Public Health in Colombia (1990-2013) A thematic approach". University of the Valley. Institute of Education and Pedagogy. Political studies and conflict resolution. 2013 Santiago de Cali, Colombia.

53. Azucena E, Amaro J, Basallo A (2004) The privatization of health in Colombia (a reflection for all). Revista de la SEMG 64: 311-315. 